\section{Letter to Editor: Progressive Brachial Plexus Palsy after Osteosynthesis of an Inveterate Clavicular Fracture}

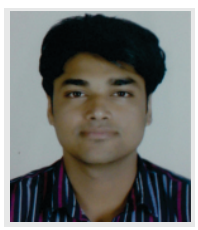

Dear sir,

I would like to raise these following points:

1. Illustration of case report in abstract was somehow different from illustration in the description as the case was explained as a 2 month old clavicle fracture in abstract \& it was explained as 4 months old in description and different other time intervals also.

2. Itrogenic compartment syndrome manifestating a week after surgery would not happen, as there was no compartment at clavicle bone, and if any local hematoma would present, that might manifest as a wound dehiscence rather that a isolated neurological symptoms.

3. lateral costo-clavicular space cannot be altered by fixing the fracture as the lateral space is maintained by coraco-clavicular ligaments which were intact in this case.

4. There was no indication for implant removal at 70 days for unstabilising the fracture site as practically it will not increase lateral costo-clavicular space.

5. Why the fracture was fixd again after a year as although the fracture fixation had created the problem.

these points indicate unreliability of facts explained in the article.

Hemendra Agrawal Central Institute Of Orthopaedics, V.M.M.C. \& Safdarjung Hospital, Newdelhi-110029, INDIA.

Address of Correspondence

Dr Hemendra K Agrawal : 1,Roop nagar first, Pushpanjali colony marg, Tonk Phatak, Jaipur, Rajasthan-302015,INDIA

Email: dr.hemendra.agrawal@gmail.com

\section{References:}

1. Rosati M, Andreani L, Poggetti A, Zampa V, Parchi P, Lisanti M. Progressive Brachial Plexus Palsy after Osteosynthesis of an Inveterate Clavicular Fracture. Journal of Orthopaedic Case Reports 2013 July-Sep ;3(3): 18-21.

\section{Conflict of Interest: Ni}

Source of Support: None

How to cite the article:

Agrawal H. Letter to Editor: Progressive Brachial Plexus Palsy after Osteosynthesis of an Inveterate Clavicular Fracture. Journal of Orthopaedic Case Reports. 2014 Jan-Mar; 4(1):44

\title{
Authors Response:Progressive Brachial Plexus Palsy after Osteosynthesis of an Inveterate Clavicular Fracture
}

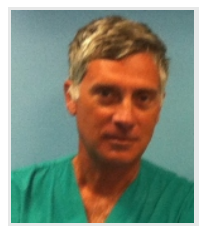

Dear sir,

First of all I want to say thank you for your questions [1] about our article [2] as it allows us to give some clarifications for better understanding of our paper:

1. The fracture was operated 4 months later the injury. The abstract report about 2 months later the injury is a mistake.

About point 2,3 and 4 we think that the only explanation for the symptoms onset was narrowing of the virtual space where brachial plexus lies. No excessive screws length, neither exuberant callus, neither an hematoma were discovered during the plate removal. We only remolded the stumps of clavicle.

5. The fracture was fixed again because medial stump cause a skin ulcer. We preferred the plate because it allowed the curettage of the non-union site. We did not use other types of synthesis (intramedullary nail, etc), indeed it was a difficult case of nonunion.

\section{Marco Rosat \\ Orthopaedic and Traumatology I Department, University of Pisa.}

Address of Correspondence

Dr Marco Rosati: Orthopaedic and Traumatology I Department, University of Pisa 050/996504 050/996501 (fax).

Email: rosati1961@gmail.com.

\section{References:}

1. Agrawal H. Letter to Editor: Progressive Brachial Plexus Palsy after Osteosynthesis of an Inveterate Clavicular Fracture. Journal of Orthopaedic Case Reports. 2014 Jan-Mar; 4(1):44

2. Rosati M, Andreani L, Poggetti A, Zampa V, Parchi P, Lisanti M. Progressive Brachial Plexus Palsy after Osteosynthesis of an Inveterate Clavicular Fracture. Journal of Orthopaedic Case Reports 2013 July-Sep;3(3): 18-21 